\title{
The effects of critical thinking instruction on training complex decision making
}

Citation for published version (APA):

Helsdingen, A. S., van den Bosch, K., van Gog, T., \& van Merriënboer, J. J. G. (2010). The effects of critical thinking instruction on training complex decision making. Human Factors: The Journal of the Human Factors and Ergonomics Society, 52(4), 537-45. https://doi.org/10.1177/0018720810377069

Document status and date:

Published: 01/08/2010

DOI:

10.1177/0018720810377069

Document Version:

Publisher's PDF, also known as Version of record

\section{Document license:}

Taverne

\section{Please check the document version of this publication:}

- A submitted manuscript is the version of the article upon submission and before peer-review. There can be important differences between the submitted version and the official published version of record.

People interested in the research are advised to contact the author for the final version of the publication, or visit the DOI to the publisher's website.

- The final author version and the galley proof are versions of the publication after peer review.

- The final published version features the final layout of the paper including the volume, issue and page numbers.

Link to publication

\footnotetext{
General rights rights.

- You may freely distribute the URL identifying the publication in the public portal. please follow below link for the End User Agreement:

www.umlib.nl/taverne-license

Take down policy

If you believe that this document breaches copyright please contact us at:

repository@maastrichtuniversity.nl

providing details and we will investigate your claim.
}

Copyright and moral rights for the publications made accessible in the public portal are retained by the authors and/or other copyright owners and it is a condition of accessing publications that users recognise and abide by the legal requirements associated with these

- Users may download and print one copy of any publication from the public portal for the purpose of private study or research.

- You may not further distribute the material or use it for any profit-making activity or commercial gain

If the publication is distributed under the terms of Article $25 \mathrm{fa}$ of the Dutch Copyright Act, indicated by the "Taverne" license above, 


\title{
The Effects of Critical Thinking Instruction on Training Complex Decision Making
}

\author{
Anne S. Helsdingen, Open University of the Netherlands, Heerlen, Netherlands, \\ Karel van den Bosch, TNO Defence, Safety, and Security, Soesterberg, Netherlands, \\ Tamara van Gog, Erasmus University Rotterdam, Netherlands, and Jeroen J. G. van \\ Merriënboer, University of Maastricht, Maastricht, Netherlands
}

Objective: Two field studies assessed the effects of critical thinking instruction on training and transfer of a complex decision-making skill.

Background: Critical thinking instruction is based on studies of how experienced decision makers approach complex problems.

Method: Participants conducted scenario-based exercises in both simplified (Study I) and high-fidelity (Study 2) training environments. In both studies, half of the participants received instruction in critical thinking. The other half conducted the same exercises but without critical thinking instruction. After the training, test scenarios were administered to both groups.

Results: The first study showed that critical thinking instruction enhanced decision outcomes during both training and the test. In the second study, critical thinking instruction benefited both decision outcomes and processes, specifically on the transfer to untrained problems.

Conclusion: The results suggest that critical thinking instruction improves decision strategy and enhances understanding of the general principles of the domain.

Application: The results of this study warrant the implementation of critical thinking instruction in training programs for professional decision makers that have to operate in complex and highly interactive, dynamic environments.

Keywords: command-and-control training, tactical decision making, decision strategies, transfer of training

Address correspondence to Anne Helsdingen, CELSTEC, OUNL, P. O. Box 2960, 6401 DL Heerlen, Netherlands; anne.helsdingen@ou.nl.

\section{HUMAN FACTORS}

Vol. 52, No. 4, August 2010, pp. 537-545.

DOI: $10.1177 / 0018720810377069$.

Copyright (C) 2010, Human Factors and Ergonomics Society.

\section{INTRODUCTION}

Studies on decision strategies of experienced decision makers in complex environments (e.g., military command and control, crisis management) have shown that experienced decision makers not only have a large body of knowledge but also apply deliberate problem-solving strategies that differ significantly from novices' strategies (Endsley, Hoffman, Kaber, \& Roth, 2007). When faced with a complex and nonroutine problem, experienced decision makers collect and critically evaluate the available evidence, seek for consistency, and test assumptions underlying their assessment of the problem (Klein, Moon, \& Hoffman, 2006). Cohen and colleagues (Cohen, Freeman, \& Thompson, 1998; Cohen, Freeman, \& Wolf, 1996; Freeman \& Cohen, 1996) developed an instructional concept that combined instruction aimed at acquisition and application of domain knowledge with instruction on explicit problem-solving strategies: critical thinking instruction.

Several evaluation studies showed promising results. After critical thinking instruction, trainees considered more observations, identified more cause-and-effect relations, provided better arguments, and made better decisions according to subject matter experts (SMEs; e.g., Cohen et al., 1998; Freeman \& Cohen, 1996). However, these studies had some limitations: They were conducted in simplified training environments, control groups did not receive any instruction or practice, and it was not established whether critical thinking instruction had effects on transfer of judgment skill to untrained tactical problems. Therefore, we conducted two field studies on the effects of critical thinking instruction on training and transfer of complex decision making in two training programs for military tactical command and control. 
Because critical thinking instruction requires trainees to focus not just on the superficial aspects of situations or on mere observations but on the underlying structures and causes, it is expected to lead to deeper understanding of the training materials (cf. Berthold, Nückles \& Renkl, 2007; Russell, 2002) and thereby to better transfer.

\section{STUDY 1}

The first study was conducted in the tactical command station of a ground-to-air defense battalion of the Royal Netherlands Air Force. The effects of critical thinking instruction on training processes and transfer test performance were assessed.

\section{Method}

Participants and design. For the first study, 16 officers of the Royal Netherlands Air Force participated voluntarily (15 male, 1 female; age, $M=32.31, S D=3.81$ ). Prior experience in ground-to-air defense tasks ranged from 1 to 5 years $(M=3.69, S D=2.14)$. The supervising project officer matched participants according to tactical education and experience and randomly assigned participants from each pair to the critical thinking condition $(n=8)$ or the control condition $(n=8)$.

Practice scenarios. Six practice scenarios were developed. The paper-and-pencil scenarios encompassed a starting point and a description of events specified in time. They required the participants to assess the geographical area, identify priorities in the area to be defended, assess threats, and perform certain actions, such as planning engagements of targets, deploying sensors and weapons, making a damage repair plan, planning for casualty transportation, reallocating resources, and making new priorities.

The scenario leader introduced the scenario events and provided feedback. Events were specified in minutes from the start (e.g., $X=$ start scenario, event $Y$ starts at $X+5 \mathrm{~min}$, event $Z$ at $X+10 \mathrm{~min}$ ), and feedback moments were specified relative to participants' reaction to events (e.g., after participants' assessment of the situation, provide feedback). Participants played the battle captain's role and the scenario leader all other roles. Each scenario took approximately $45 \mathrm{~min}$ to complete.
Critical thinking instruction. In the critical thinking condition, participants received a paperbased instruction, explaining the four steps in the process of critical thinking (Cohen et al., 1998): (a) creating a story of the situation, (b) testing that story for conflicting or missing information, (c) evaluating its plausibility and finding alternative stories (i.e., contingency plans), and (d) quick consideration of the need to decide immediately or spend more time on the critical thinking process.

Participants were instructed to think aloud during the whole process (see Ericsson \& Simon, 1993). Besides the textual explanation, a handout with a graphic representation of the four steps and two demonstrations of critical thinking in real-world situations were provided. In each demonstration, two scenario leaders showed how critical thinking should be used in the scenarios; one of them played the role of participant (i.e., the battle captain), and one of them played the other roles.

Feedback during the practice scenarios was focused on participants' critical thinking processes. Scenario leaders closely monitored participants'verbalizations of their decision-making processes and matched them with the required assessments as specified in the scenario. If the participant identified missing or wrong assessments, they would ask open-ended questions to encourage the participant to critically reflect on her or his own decision process, acknowledge the missing or wrong assessment, and take recuperating actions. When participants were adequately engaged in the critical thinking process, scenario leaders only made encouraging remarks (e.g., "Very well" or "I understand"). Scenario leaders did not provide any other feedback or information.

Control group instruction. The control group participants were given a presentation of the organization and projects of the institute, where two of the authors worked to engage them during the critical thinking instruction of the other group. They also received a short introduction regarding the purpose and context of the tactical practice scenarios they were about to receive. Furthermore, two example scenarios were demonstrated by two scenario leaders. These scenarios were being played as normal command post exercises, that is, without critical thinking. 
During execution of the practice scenarios, participants received outcome feedback only (e.g., "That was a good assessment" or "You failed to destroy the target").

Test scenarios. The test scenarios were two paper-and-pencil scenarios in which the participants again played the role of battle captain and the scenario leader covered all other roles. Neither outcome feedback nor process feedback was provided during the execution of the test scenarios. Participants were required to think aloud during execution of the test scenarios.

Command and Control Process Measurement Tool (C2PMT). Two types of performance measures were gathered during the practice and test scenarios: (a) outcome measures to assess the quantity and quality of the end result and (b) process measures to evaluate the strategies, steps, and procedures used to accomplish the task. According to the C2PMT (Van Berlo \& Schraagen, 2000), performance indicators were specified for both the outcomes and process measures, enabling the scenario leaders to observe and interpret the decision-making processes and outcomes.

The performance indicators were easily scored in terms of whether the behavior was observed or not; this was indicated in the respective column (yes or no), and an overall grading (ranging from $1=$ very poor to $10=$ excellent ) for that performance measure was determined (see Table 1). Prior to the experiment, scenario leaders had used the results of a pilot study (using the same scenarios but with different participants) to reach a common understanding of assigning grades.

Procedure. The experiment had a duration of approximately $10 \mathrm{hr}$ and was run in five daily 2-hr sessions with one or two participants at the same time. In the first session, participants received the critical thinking instruction or general presentation followed by the two demonstration scenarios. In the three subsequent training sessions, two practice scenarios were played each time, with a 15 -min break between the scenarios.

The order of the six practice scenarios was randomly selected from all possible scenario sequences for each participant. Consecutive practice scenarios were facilitated by different scenario leaders; that is, participants practiced three scenarios with one scenario leader and the other three with another scenario leader.

The scenario leaders provided participants with all relevant scenario input, reacted to their decisions according to the scenario, provided feedback, and evaluated performance. The participants were required to verbalize their thoughts during the scenarios to provide the scenario leader insight into their (critical) thinking processes, enabling the evaluation of participants' performance and provision of feedback. Approximately two to three times during a practice scenario, the scenario leader provided feedback, during which the scenario was "frozen" for a few minutes. Scoring of the performance indicators was done continuously during the scenario. Thus, when participants were stating the right priorities or providing a logical argument for an assessment, these performance indicators for the performance measure "quality of plans" were ticked off. These indicators served as a support tool for the scenario leader to be able to grade (between 1 and 10) performance measures at the end of a scenario.

In the fifth session, two test scenarios were played. Order and assignment of the test scenarios to scenario leaders were balanced. Again, all participants were asked to think aloud; however, no feedback was given. Participants' verbalizations of their (critical) thinking were used to grade performance.

Data analysis. Quality of actions and contingency plans were scored and aggregated into a measure of the decision outcome (Cronbach's $\alpha=.76)$. Similarly, information processing and argumentation were graded and aggregated into a measure of the decision process (Cronbach's $\alpha=.93$ ).

\section{Results}

Measures of decision process and outcome were analyzed with the use of a $t$ test for two dependent samples. In all analyses reported in the following paragraphs, a significance level of .05 is set, and Hedge's $g$ with $95 \%$ confidence interval (CI) is reported as a measure of effect size, and because of small sample sizes, it was corrected for bias with the use of the method reported in Hedges and Olkin (1985, p. 80). 
TABLE 1: Performance Measures and Performance Indicators

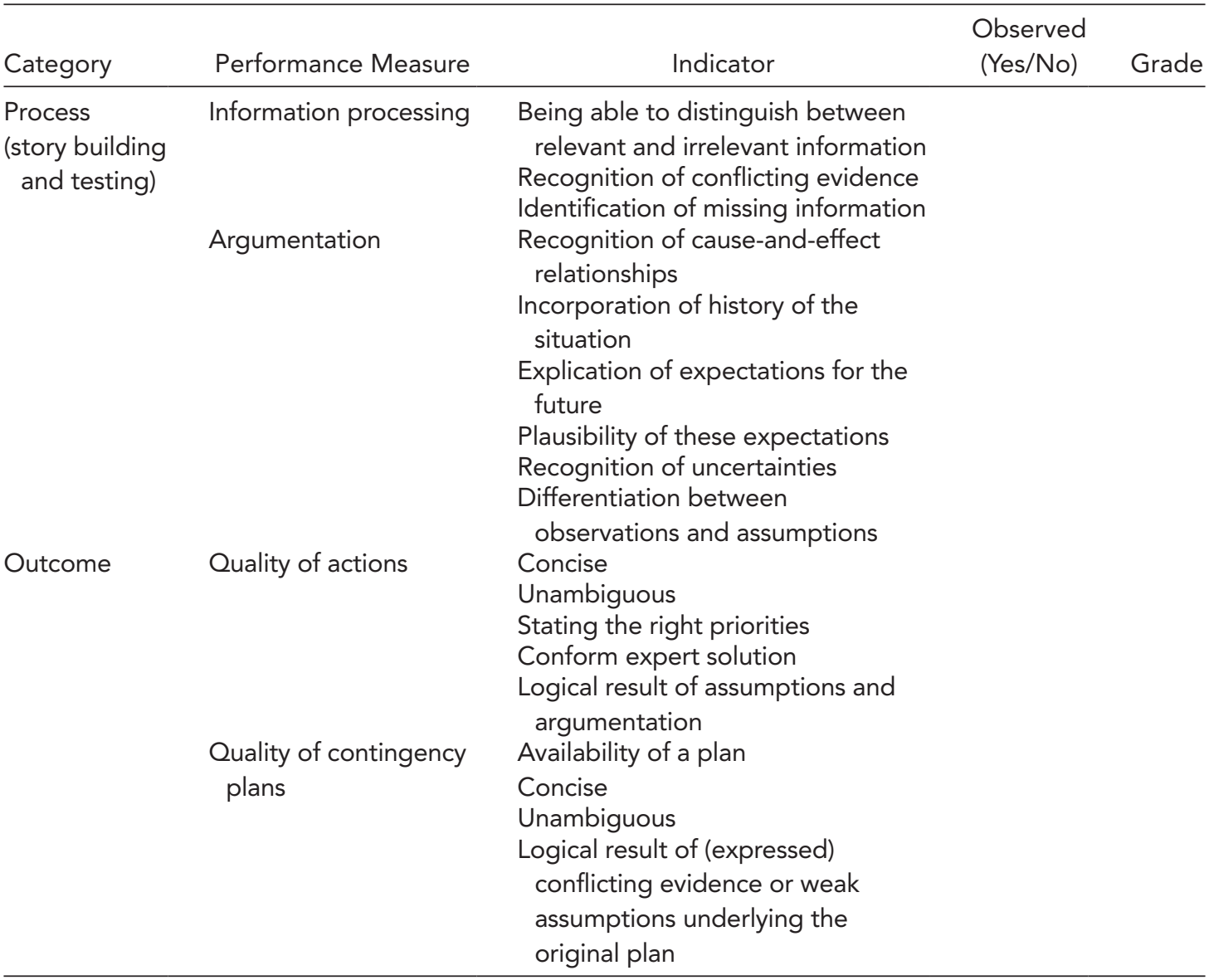

Training. The means of the decision process and outcome measures during training are presented in Figure 1. Paired $t$ tests showed that critical thinking had an effect on decision outcome, $t(7)=-3.25, p=.01, g=1.09,95 \%$ CI $[0.20,1.98]$, with participants in the critical thinking group reaching higher grades $(M=$ $5.65, S D=1.62)$ than participants in the control group $(M=3.78, S D=0.31)$. However, no significant effects were found of critical thinking on decision process, $t(7)=1.65, n s$.

Test. The means of decision process and outcome measures are presented in Figure 1. Paired $t$ tests showed a small effect of critical thinking instruction on decision outcome, $t(7)=-2.35$, $p=.05, g=0.63,95 \%$ CI $[-0.08,1.34]$, with the critical thinking group performing better $(M=4.94$, $S D=1.65)$ than the control group $(M=3.44$,
$S D=1.30)$. Again, no effects were found of critical thinking on decision process measures, $t(7)=1.61, n s$.

\section{Discussion}

Participants in the critical thinking condition made better decisions than the control group during training, and this result seemed to carry over into the test. However, critical thinking did not benefit the processes of decision making; it benefited only the decision outcomes. Although the process measures failed to show statistically significant effects of critical thinking, a trend can be observed from Figure 1 that suggests that participants from the critical thinking group obtained slightly higher grades than the control group.

The higher grades may have been given because scenario leaders' scoring was biased by 


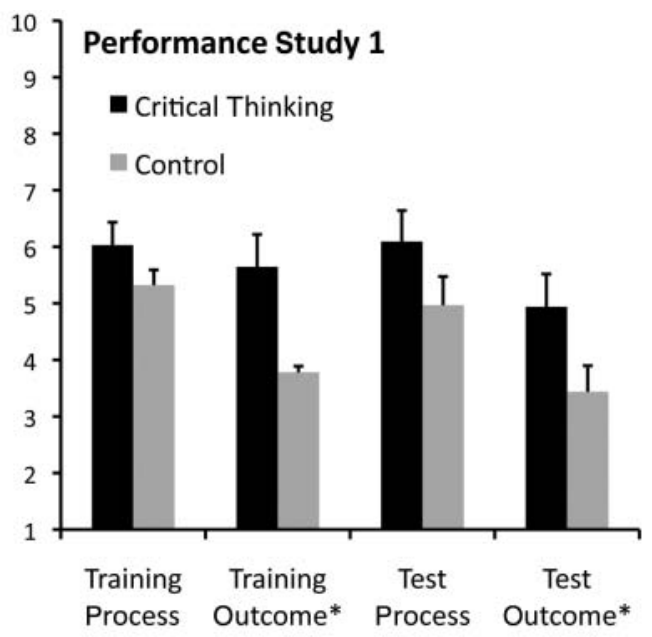

Figure 1. Means and standard deviations of critical thinking group and control group scores during training and on the test. $*$ significant at $5 \% .1=$ terrible, $2=$ bad, $3=$ very weak, $4=$ weak, $5=$ failing, $6=$ passed , $7=$ okay, $8=\operatorname{good}, 9=$ excellent, $10=$ perfect .

their knowledge of the instructional intervention, whereby they favored the decision strategies of the control group because it did not receive critical thinking support. Nevertheless, the focus of the critical thinking approach on critical assumptions, conflict, missing information, and contingencies is likely to have resulted in the better decision outcomes, although with average grades near 5 (out of maximum 10), even the critical thinking group does not show adequate performance.

The results suggest that the critical thinking approach might be a useful tool for improving the quality of training tactical decision making, as earlier explorative studies indicated (e.g., Cohen et al., 1996; Freeman \& Cohen, 1996; Klein, McClosky, Pliske, \& Schmitt, J. (1997). However, this study had some limitations.

First, scenario leaders were the evaluators of the practice and test scenarios, so their scoring may have been biased. Second, the effect of the instruction has been studied in a simplified task environment. For reasons of transfer, it is necessary to investigate whether critical thinking skills can be successfully trained in high-fidelity task environments. Finally, in this study, the test tasks were rather similar to the training tasks.
When critical thinking leads to deeper understanding of the training material, we would also expect benefits of this type of instruction for test tasks that are different from the training tasks. Hence, a second study was conducted to address these issues with the use of independent assessments and a more realistic task environment.

\section{STUDY 2}

This study was conducted in the domains of anti-air warfare and anti-surface warfare at the Operational School of the Royal Netherlands Navy. Teams of one officer and one petty officer played single-ship, single-threat scenarios in a high-fidelity tactical simulator.

\section{Method}

Participants. For the second study, 16 officers of the Royal Netherlands Navy volunteered to participate in the experiment (15 male, 1 female; age, $M=36.08, S D=6.07$ ) and had prior sailing experience ranging from 2 to 17 years $(M=$ $10.23, S D=5.57$ ). The supervising project officer matched participants according to their tactical education and experience and assigned participants from each pair randomly to the critical thinking condition $(n=8)$ and control condition $(n=8)$.

Practice scenarios. Developed were four anti-surface warfare practice scenarios of approximately $120 \mathrm{~min}$ each. Of these scenarios, two were paper-and pencil scenarios, and two were scenarios to be run in the high-fidelity tactical simulator. All four scenarios had a structure similar to the scenarios in Study 1. Participants played the role of principal warfare officer and assistant, and the scenario leader played all other roles. The assistant was responsible for tactical picture compilation, interacted with the operators or the system to gather all information, and presented that information graphically to the principal warfare officer, who interpreted the picture and decided on which actions (e.g., maneuvers, engagements) to take.

Critical thinking instruction. Critical thinking instruction was identical to that in Study 1.

Control group instruction. Control group instruction was identical to that in Study 1. 
Test scenarios. Two test scenarios were developed: (a) a posttest scenario that was a variation on the practice scenarios (i.e., anti-surface warfare) and (b) a transfer scenario that was different from the practice scenarios on both superficial and structural level (anti-air warfare) scenarios. On Royal Netherlands Navy frigates, air and surface warfare are different expertise areas and are managed by different officers. Both test scenarios were played in the tactical simulator. No feedback was provided during execution of the test scenarios.

Performance measures. The same performance measures as in Study 1 were used. In addition, time management and team skills were graded (cf. Smith-Jentsch, Zeisig, Acton, \& McPherson, 1998), but these were left out from our analyses. Because scenario leaders and evaluators were used to the official North American Treaty Organization scale, it was decided to use this 4-point scale, in which $1=$ unsatisfactory, 2 = marginal, 3 = satisfactory, and 4 = excellent (see Van Berlo \& Schraagen, 2000), to grade all performance measures.

Procedure. Prior to the study, scenario leaders assigned to critical thinking teams were extensively briefed on the critical thinking instruction as well as on how to support the teams in the application of the critical thinking processes. Scenario leaders assigned to control teams were not informed about the concept of critical thinking and were instructed to provide outcome feedback. The experimenter instructed the two SMEs who evaluated the transfer tests on the scoring procedure and how to use the scale. These SMEs were blind to the conditions and were not informed about the concept of critical thinking instruction nor of the purpose and design of the study. Again, scenarios of a pilot study were used to arrive at a common interpretation of performance indicators.

The experiment lasted approximately $20 \mathrm{hr}$ and was run in five daily sessions of approximately $4 \mathrm{hr}$. In the first session, participants received the instruction to play the scenarios as a normal command-and-control exercise. Participants in the critical thinking group received a critical thinking tutorial, followed by a demonstration in which the scenario leader showed how critical thinking should be used in the scenarios. The control group witnessed a presentation of the institute where two of the authors work. After that, a demonstration was given of the same example scenario as the critical thinking group received but without critical thinking. In the subsequent training sessions, two practice scenarios were played each day, with a 1-hr break in between the scenarios.

The order of practice scenarios was predefined and similar for all participants, and scenario leaders were assigned to scenarios because specific expertise was required for specific scenarios. As in Study 1, in the first two scenarios, scenario leaders provided participants with all relevant scenario input, reacted to their decisions according to the scenario, provided feedback, and evaluated performance on the basis of participants' thinking aloud. The two subsequent practice scenarios were played in the simulator, thus leaving only giving feedback and evaluating performance for the scenario leaders.

Approximately four to five times during a practice scenario, the scenario leader provided feedback and "froze" the scenario for a few minutes. Scoring of the performance indicators was done during the scenario. The performance measures were graded four times during the scenario; markers in the scenario description prompted the scenario leader to do so.

In the fourth session, the test scenarios were played in the simulator. Order of the test scenarios was balanced per session. Thus, half of the participants played a transfer test scenario prior to the posttest scenario and the other half vice versa. All participants were asked to think aloud to enable performance evaluation, but no feedback was given. SMEs scored the performance indicators during execution of the scenario when a participant exhibited the behavior as in Study 1, and markers in the paper-based scenario description prompted the evaluator to grade all performance measures at that particular moment, four times per scenario.

Data analysis. Participants were graded individually. The mean grades on information processing, argumentation, quality of action plans, and quality of contingency plans were calculated for each team of two participants for the 
four training scenarios and test scenarios. Scores for information processing and argumentation were aggregated into a measure of decision process (Cronbach's $\alpha=.88$ ). Decision outcome was an aggregate measure of scores on quality of action and contingency plans (Cronbach's $\alpha=.84$ ).

\section{Results}

The effects of critical thinking on the decision process and outcome were analyzed with the use of $t$ tests for two dependent samples. In all analyses reported in the following paragraphs, a significance level of .05 is set, and Hedge's $g$ with $95 \%$ CI is reported as effect size measure and, because of the small sample size, corrected for bias with the use of the method reported in Hedges and Olkin (1985, p. 80).

Training. Analysis of the process, $t(3)=-0.31$, $n s$, and outcome measures, $t(3)=-1.00, n s$, showed no significant effects of critical thinking during training.

Tests. Figure 2 presents the mean grades on all performance measures for both conditions in the tests. Paired $t$ tests showed that none of the performance measures on the posttest were affected by critical thinking instruction: decision process, $t(3)=.61, n s$, and outcome, $t(3)=$ .67, ns.

Performance measures on the transfer test were significantly affected by critical thinking instruction. On the decision process, the critical thinking teams received significantly higher grades $(M=2.88, S D=0.37)$ than the control teams $(M=2.20, S D=0.23), t(3)=-4.23, p=.03$, $g=1.91,95 \%$ CI $[0.98,2.83]$, and the decision outcomes of critical thinking teams were also higher $(M=2.42, S D=0.36)$ than those of the control teams $(M=1.69, S D=0.39), t(3)=$ $-4.70, p=.02, g=1.67,95 \%$ CI $[0.76,2.58]$. After the use of the Benjamini-Hocherg procedure (Benjamini \& Hochberg, 1995) to correct for a false discovery rate, the effects on the performance measures remain significant.

\section{Discussion}

This study showed clear benefits of critical thinking instruction on transfer to a task that differed from the training scenarios. Thus, it seems that the critical thinking instruction has

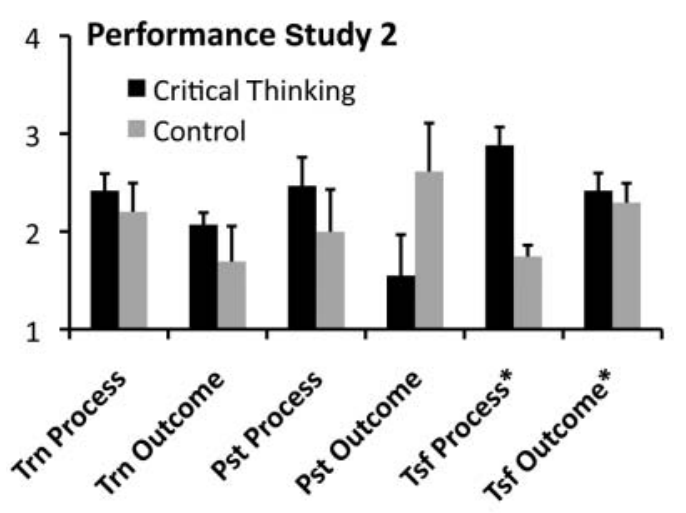

Figure 2. Means and standard deviations of participants of the critical thinking group and control group during training, on the posttest, and on the transfer test. * significant at $5 \%$. Trn $=$ training; Pst $=$ posttest; Tsf $=$ transfer. $1=$ unsatisfactory, $2=$ marginal, $3=$ satisfactory, $4=$ excellent.

provided the participants with a better strategy to approach new problems in the transfer test scenario. The study failed to show benefit of critical thinking instruction on the posttest scenario. This difference from Study 1 may be because the tactical problems in the posttest scenario closely resembled those in the training scenario, providing participants with the opportunity to rely on their specific memories of similar cases they had experienced during training. As Cohen et al. (1998) argued, critical thinking is not expected to increase decision quality for routine problems, probably because then there is no need to "search for patterns in the training material, restructuring of problem representations, or metacognitive processes" (Schnotz \& Kürschner, 2007, p. 503).

\section{GENERAL DISCUSSION}

The two field studies reported in this article examined the effects of critical thinking instruction on training complex decision making in command and control. With respect to participants' performance, it was hypothesized that critical thinking instruction yields better training outcomes than does training without critical thinking, that is, higher test performance. The studies support this hypothesis. 
Our findings are consistent with those of studies on the effects of critical thinking instruction on command-and-control decision making (Freeman \& Cohen, 1996), nursing (Forneris \& Peden-McAlpine, 2006), medical diagnosis (Klein, 1998), and management (Yeo, 2007). Not only do participants show improved decision processes, but their decision outcomes, measured in terms of, for example, the quality of plans, were also better. We have shown that critical thinking instruction can also be successfully applied in training decisionmaking skills in interactive and dynamic highfidelity simulators and renders better results than does merely conducting exercises in these simulator environments.

The performance gains can probably be partly ascribed to participants' being able to apply a better decision strategy as a result of the critical thinking instruction (Cohen et al., 1996, 1998; Freeman \& Cohen, 1996). As Halpern (1997) has shown, when students are taught critical thinking skills, they are less likely to make the typical decision mistakes caused, for example, by confirmation bias.

That we found critical thinking instruction to have an effect on performance on an untrained transfer test scenario in Study 2 may be an indication that participants gained a deeper understanding of the task content that enabled them to solve new decision problems that differed from the training problems (cf. van Merriënboer, 1997; van Merriënboer \& Paas, 1990). An interesting question for future research that cannot be answered on the basis of our data is exactly what aspects of critical thinking instruction lead to a deeper level of understanding? Possibly, the instruction triggers processes of self-explanation or reflection on the structure of the task (Chi, Bassok, Lewis, Reimann, \& Glaser, 1989; Renkl, 1997). It might be interesting to disentangle the contributions of different processes to training and transfer.

There are some limitations of this field study: First of all, in Study 1, the test performance evaluators were also the scenario leaders and thus were informed about the experimental manipulation. Second, although the evaluators of test performance were blind to the experimental manipulation in Study 2, scenario leaders and evaluators could not be balanced across training or test scenarios, because the specific training materials required SMEs to evaluate them and because the scenario leaders instructing the control group had to remain uninformed about the critical thinking instruction to prevent them from introducing critical thinking elements in the control group instruction. This condition may have introduced some confound in the study. Third, the small sample size, especially in Study 2, limits the transferability of our findings to other training programs.

Nevertheless, in combination with previous studies, our field studies seem to warrant implementation of critical thinking instruction in training programs. However, implementation studies with larger numbers of participants are needed to provide answers to important questions concerning how critical thinking instruction can be integrated into an existing curriculum, what practice instructors need for successful application, and what the long-term effects are on decisionmaking performance.

\section{KEY POINTS}

- Critical thinking instruction explicitly teaches strategies such as story building, self-explanation, and reflection when training military tactical decision making.

- Critical thinking instruction can be successfully taught to relative novice military decision makers.

- Critical thinking instruction benefits test performance when compared with standard scenariobased training, especially transfer to untrained tactical problems.

\section{REFERENCES}

Benjamini, Y., \& Hochberg, Y. (1995). Controlling the false discovery rate: A practical and powerful approach to multiple testing. Journal of Royal the Statistical Society: Series B (Statistical Methodology), 57, 289-300.

Berthold, K., Nückles, M., \& Renkl, A. (2007). Do learning protocols support learning strategies and outcomes? The role of cognitive and metacognitive prompts. Learning and Instruction, 17, 564-577.

Chi, M. T. H., Bassok, M., Lewis, M. W., Reimann, P., \& Glaser, R. (1989). Self-explanations: How students study and use examples in learning to solve problems. Cognitive Science, 13, 145-182.

Cohen, M. S., Freeman, J. T., \& Thompson, B. T. (1998). Critical thinking skills in tactical decision making: A model and a training strategy. In J. A. Cannon-Bowers \& E. Salas (Eds.), Making decisions under stress: Implications for individual and team training (pp. 155-190). Washington, DC: American Psychological Association. 
Cohen, M. S., Freeman, J. T., \& Wolf, S. (1996). Meta-recognition in time stressed decision making: Recognizing, critiquing, and correcting. Human Factors, 38, 206-219.

Endsley, M. R., Hoffman, R., Kaber, D. B., \& Roth, E. (2007). Cognitive engineering and decision making: An overview and future course. Journal of Cognitive Engineering and Decision Making, 1, 1-21.

Ericsson, K. A., \& Simon, H. A. (1993). Protocol analysis: Verbal reports as data (Rev. ed.). Cambridge, MA: MIT Press.

Forneris, S. G., \& Peden-McAlpine, C. J. (2006). Contextual learning: A reflective learning intervention for nursing education. International Journal of Nursing Education Scholarship, 3, 1-18.

Freeman, J. T., \& Cohen, M. S. (1996). Training for complex decisionmaking: A test of instruction based on the recognition/metacognition model. Proceedings of the 3rd International Command and Control Research and Technology Symposium 1996. Retrieved from http://www.cog-tech.com/papers/c2/c2_1996.pdf

Halpern, D. F. (1997). Students need "reality checks." Education Digest, 63, 24-26.

Hedges, L., \& Olkin, I. (1985). Statistical methods for meta-analysis. New York, NY: Academic Press

Klein, G. A. (1998). Sources of power: How people make decisions. Cambridge, MA: MIT Press.

Klein, G. A., McClosky, M., Pliske, R., \& Schmitt, J. (1997) Decision skills in training. In Proceedings of the Human Factors Society, 41th Annual Meeting, Albaquerque, AL (pp. 182-185). Santa Monica, CA: HFES.

Klein, G. A., Moon, B. A., \& Hoffman, R. R. (2006). Making sense of sensemaking 1: Alternative perspectives. IEEE Intelligent Systems, 21, 70-73.

Renkl, A. (1997). Learning from worked-out examples: A study on individual differences. Cognitive Science, 21, 1-29.

Russell, A. (2002, April). The role of epistemic agency and knowledge building discourse to foster interprofessional practice in a Canadian hospital. Paper presented at the annual conference of the American Educational Research Association, New Orleans, LA. Retrieved from http://www.ikit.org/fulltext/ 2002AERAAnn.pdf

Schnotz, W., \& Kürschner, C. (2007). A reconsideration of cognitive load theory. Educational Psychology Review, 19, 469-508.

Smith-Jentsch, K. A., Zeisig, R. L., Acton, B., \& McPherson, J. A. (1998). Team dimensional training: A strategy for guided team self correction. In J. A. Cannon-Bowers \& E. Salas (Eds.), Making decisions under stress: Implications for individual and team training (pp. 271-298). Washington, DC: American Psychological Association.

Van Berlo, M. P. W., \& Schraagen, J. M. C. (2000). A generic assessment tool for evaluating $\mathrm{C} 2$ exercises. In Proceedings of the Interservice/Industry Training, Simulation and Education Conference (I/ITSEC) 2000 (pp. 652-660) [CD-ROM]. Arlington, VA: National Training and Simulation Association. van Merriënboer, J. J. G. (1997). Training complex cognitive skills: A four component instructional design model for technical training. Englewood Cliffs, NJ: Educational Technology.

van Merriënboer, J. J. G., \& Paas, F. (1990). Automation and schema acquisition in learning elementary computer programming: Implications for the design of practice. Computers in Human Behavior, 6, 273-289.

Yeo, R. K. (2007). (Re)viewing problem-based learning: An exploratory study on the perceptions of its applicability to the workplace. Journal of Managerial Psychology, 22, 369-391.

Anne S. Helsdingen received her $\mathrm{PhD}$ in educational technology from the Open University of the Netherlands in 2008. She is a researcher at the Centre for Learning Sciences and Technologies at the Open University of the Netherlands in Heerlen.

Karel van den Bosch received his $\mathrm{PhD}$ in psychology from the Radboud University Nijmegen in the Netherlands in 1991. He is a senior researcher at TNO Defence, Safety, and Security in Soesterberg.

Tamara van Gog is an associate professor of educational psychology at the Institute of Psychology of the Erasmus University Rotterdam in the Netherlands. In 2006, she received her $\mathrm{PhD}$ in educational technology from the Open University of the Netherlands in Heerlen. At the time this work was conducted, Tamara van Gog was affiliated with the Centre for Learning Sciences and Technologies at the Open University of the Netherlands in Heerlen.

Jeroen J. G. van Merriënboer is a full professor in educational psychology at the School of Health Professions Education at the University of Maastricht in the Netherlands. He received his $\mathrm{PhD}$ in educational technology from the University of Twente in Enschede in 1990.

Date received: August 14, 2009

Date accepted: June 2, 2010 